\title{
El lugar de la Iglesia en el mundo moderno \\ Una mirada cronológica a las vocaciones sacerdotales, los laicos $y$ los pobres en el ministerio de San Alberto Hurtado, S.J.
}

Francisco Jiménez,

\section{Introducción}

El presente artículo, síntesis de un trabajo más extenso y que constituyó mi tesis de Licencia en Teología, recoge la lectura cronológica de todos los escritos de San Alberto Hurtado que conservamos en el archivo de la provincia chilena de la Compañía de Jesús y que han sido sistematizados, datados y digitalizados por el Centro de Estudios y Documentación San Alberto Hurtado de la Pontificia Universidad Católica. Después de esta lectura cronológica, he llegado a la convicción de que una de las inquietudes más urgentes del Padre Hurtado tuvo que ver con la suerte de la Iglesia en el mundo moderno. Su trabajo con los jóvenes y las vocaciones sacerdotales, primero, y con laicos y obreros, después, quiso responder a la crisis generada en la Iglesia ante los cambios traídos por la modernidad y la secularización, crisis que el Padre Hurtado vivió como apremiante.

De acuerdo con esto, pretendo mostrar en esta investigación que el Padre Hurtado se entregó al ministerio vocacional porque vio en la presencia de más y mejores sacerdotes una solución privilegiada a la crisis que vivía la sociedad y la Iglesia con el asentamiento de la modernidad y la creciente secularización. A través de un recorrido cronológico y narrativo, iré mostrando cómo Alberto Hurtado fue sintonizando con los cambios que se produjeron en la Iglesia, desde una concepción clerical y hierática a una más comunitaria y participativa, en la que la sintonía con los gozos y las esperanzas, las tristezas y las angustias del mundo moderno, especialmente de los más pobres, y la confianza en el laicado se fueron haciendo cada vez más relevantes. 


\section{Contra la Crisis, Más Sacerdotes. Ministerio entre 1936 y 1940 \\ Crisis social, crisis moral}

En febrero de 1936, Alberto Hurtado llegó a Chile, tras 11 años de formación jesuita. Y no tardó mucho en llenarse de trabajo. «Estoy con trabajo hasta la coronilla», comentaba a tres meses de su arribo ${ }^{1}$. Sus tareas principales se concentraron en el Colegio San Ignacio; allí fue nombrado profesor de Apologética para los alumnos de $6^{\circ}$ (el último año), Director de la Congregación de la Inmaculada Concepción y San Luis Gonzaga para alumnos mayores, y director espiritual. Asimismo, comenzó a hacer clases de Psicología Pedagógica en la Universidad Católica y en el Seminario Mayor de Santiago. Poco a poco se fue haciendo popular, especialmente entre los alumnos mayores del colegio y los universitarios, para los que empezó a organizar continuas tandas de Ejercicios Espirituales. Su trato fácil, su sonrisa y el modo interpelante con que presentaba el cristianismo hicieron que todas las tardes su pieza se viera invadida por jóvenes que lo buscaban para conversar ${ }^{2}$.

Hurtado sonreía, pero estaba preocupado. Le inquietaba lo que había visto en Europa y lo que estaba viendo en Chile. Era cosa de detenerse y observar con atención: según su parecer, el ser humano estaba sumido en una profunda crisis, quizá la peor de su historia; una crisis social, una crisis moral. Comenzó a tomar nota de lo que veía. Mientras que en Europa se gestaba nuevamente la guerra, podía constatar que en Chile la vida cristiana había disminuido en intensidad, menos católicos en misa, menos confesiones, ignorancia inexcusable acerca de las verdades fundamentales de la fe. Y lo peor, la frialdad, la indiferencia religiosa, especialmente entre los hombres. La fe cristiana se volvía irrelevante. Caminando por

1 Carta a Jorge Fernández, 1936, APH s62y097. De acuerdo con la sistematización hecha por el Centro de Estudios y Documentación, Carta a Jorge Fernández corresponde al nombre del documento, 1936 al año de composición, y APH s62y097 al número de ubicación del documento en el archivo de la provincia de Chile de la Compañía de Jesús, en este caso, Archivo Padre Hurtado, sobre 62, documento 097.

2 J. M. Restrepo, SJ, Informe privado a la nunciatura, octubre 5 de 1939. Este informe es parte de la información que recabó el Nuncio en Chile, Monseñor Aldo Laghi, entre abril y octubre de 1939, para determinar las condiciones de Alberto Hurtado para el episcopado. El texto citado se encuentra en Roma, en el archivo de la Congregación de los Obispos, y es una traducción española hecha en base a la traducción italiana (el original no se conserva). Yo he tenido a la vista una síntesis inédita de estos informes hecha por el padre Samuel Fernández. 
Santiago enumeró sorprendido la cantidad de biógrafos instalados en la ciudad, el espacio religioso era reemplazado por la diversión y la falsedad de una vida mundana proyectada en telones. Los patronatos y los centros sociales en los que había trabajado en su niñez y juventud habían prácticamente desaparecido. El descuido con el pobre le parecía insultante, el lujo en el centro de Santiago contrastaba con la miseria y la enfermedad en la periferia, los niños vagaban hambrientos frente a la mirada despreocupada de las familias que salían de misa en la Iglesia San Ignacio. Tanta gente sin educación cristiana, tantos niños de liceos públicos destinados a engrosar las filas de los enemigos de la Iglesia, porque nadie les mostraba la verdad de Jesucristo; y en las universidades el panorama no se presentaba mejor, esos primeros meses se había dado cuenta que Santiago, Valparaíso y Concepción no tenían un solo sacerdote exclusivamente dedicado a la formación de los estudiantes universitarios. La crisis, una crisis de cristianismo, era evidente para él ${ }^{3}$.

Un mes llevaba el Padre Hurtado en Chile, cuando, en marzo de 1936, el viceprovincial jesuita, José Llusá, dispuso en reunión con su consulta emprender una campaña de fomento de vocaciones; para ello creó una comisión especial que estudiaría el asunto y propondría líneas de acción. El Padre Hurtado fue parte de esa comisión ${ }^{4}$. Unos pocos meses después, en septiembre, Hurtado terminó de escribir un pequeño folleto llamado La Crisis Sacerdotal en Chile y en diciembre lo publicó a través de la editorial Splendor. Se trataba de un "grito de angustia» ante una crisis «que no puede menos de hacernos temblans. Su recopilación de datos acerca de la descristianización del mundo y la falta de sacerdotes, especialmente de Chile, quería remecer, despertar, mover, ante lo que él consideraba un «mundo al borde del abismo» ${ }^{5}$.

En estos juicios, el Padre Hurtado exudaba el ambiente eclesial. Esta mirada crítica al mundo moderno y su creciente secularización encontraba una raíz en la posición que la Iglesia había incubado siglos antes frente a la reforma luterana y posteriormente ante la Revolución francesa y el influjo de las ideas liberales. Estas ideas, que se institucionalizaron en los siglos

3 A. Hurtado, La Crisis Sacerdotal en Chile (Santiago 1936); [El problema social], [1936], APH s53y15b; La situación social en Chile, [1936], APH s27y03.

4 Libro de la Consulta de la región chilena de la Compañía de Jesús, marzo 7, 1936, p. 120. Libro ubicado en el Archivo de la provincia chilena de la Compañía de Jesús en Santiago de Chile.

5 A. Hurtado, La Crisis Sacerdotal en Chile, 4. 
XVIII y XIX y que cuestionaron el fundamento religioso de la sociedad y relativizaron el poder temporal de la Iglesia, la pusieron a la defensiva y en la necesidad de defender su doctrina y su influencia en la sociedad moderna. La Iglesia proclamó la vigencia de sus valores y las graves consecuencias que tendría su pérdida para la sociedad en su conjunto. Alberto Hurtado vivió su niñez y su juventud en este ambiente restauracionista y apologético que caracterizó a la Iglesia del siglo XIX y primera mitad del siglo XX. Su educación religiosa, recibida de una familia aristocrática y tradicionalmente católica, estaba teñida de la disputa antiliberal, que se esforzaba por mostrar un cristianismo triunfante y glorioso, capaz de vencer las ideas secularizantes. Durante gran parte de su formación jesuita, Hurtado recibió la misma impronta, salvo en Lovaina, donde respiró aires renovadores que marcarán su senda, como se verá más adelante.

El discurso eclesial que encontró el Padre Hurtado a su regreso a Chile en 1936 no fue demasiado diferente del que conoció antes de partir. Aunque la separación de la Iglesia y el Estado, operada en 1925, había calmado los ánimos de las «disputas religiosas», parte importante de pastores y laicos invertían aún energías en la reivindicación y defensa de los derechos de la Iglesia en la arena pública. La Iglesia entera, y Hurtado en ella, respiraban la crisis de fondo, la descristianización no se detenía. Era necesario hacer algo.

\section{Las vocaciones sacerdotales como solución}

La Crisis Sacerdotal en Chile salió a la luz pública en ese tono, como un llamado de atención urgente a hacer algo. Si no ponemos remedio, decía Alberto Hurtado, los católicos «tendremos que resignarnos a ver cómo la fe cristiana, fundamento del orden y grandeza, va desapareciendo de las inteligencias y de los corazones y dentro de no mucho tiempo Chile habrá de dejado de ser un país católico» ${ }^{6}$. La solución de Hurtado a la crisis era clara y apremiante: el fondo religioso del pueblo chileno volvería a vibrar si se contaba con sacerdotes suficientes para hacerse oír. La clave para revertir el proceso de irrelevancia que amenazaba a la fe católica era el surgimiento de vocaciones, nuevos obreros capaces de consagrarse «a continuar en el mundo la obra de Cristo» ${ }^{7}$. El Padre Hurtado interpelaba al joven directamente: «Tú que estás en la edad de las resoluciones definitivas, piensa que Cristo llama a los jóvenes como

\footnotetext{
6 A. Hurtado, La Crisis Sacerdotal en Chile, 24.

7 Ibídem.
} 
tú a extender el Reino de Dios en las almas...» ${ }^{8}$. La Crisis Sacerdotal en Chile fue un folleto vocacional que quiso recordar dramáticamente a los jóvenes y a las familias católicas que el número de ministros ordenados era clave en el futuro de la Iglesia.

Este convencimiento atravesaba la Iglesia entera. Era necesario trabajar con ahínco por las vocaciones al sacerdocio. El Papa Pío XI, en diciembre de 1935, había promulgado su Encíclica Ad Catholici Sacerdotii sobre el sacerdocio católico, y había recordado la importancia de orar y trabajar para que el Señor enviara más obreros a su mies, con el convencimiento de que, incluso en tiempos poco propicios para el florecimiento de vocaciones, Dios no dejaba de ser generoso en sacerdotes buenos y santos?. En la Compañía de Jesús, a pesar de que el número de vocaciones fue en constante aumento después de la restauración (en 1815 eran 600, en 1914 alcanzaban los 16.000, y en 1936 eran ya $25.000^{10}$ ), la sensación de falta de miembros suficientes para la misión era permanente. En junio de 1934, el Prepósito General, Padre Wlodimir Ledochowski, había enviado una carta a los jesuitas en Latinoamérica para animar la promoción de vocaciones. Allí, Ledochowski se quejaba de que los obispos apelaban a los jesuitas para emprender trabajos de suma importancia para la gloria de Dios, pero que a menudo no podían «aceptar porque no tenemos el personal suficientes ${ }^{11}$. Por ello, alentaba a cada jesuita a asumir la promoción vocacional como una misión personal, ya que la fe católica se encontraba en peligro, atacada continuamente por sus enemigos, principalmente protestantes y comunistas.

En los años treinta, las vocaciones a la Compañía de Jesús en Chile no eran escasas. Tener más vocaciones chilenas parece haber sido una prioridad de los jesuitas en las primeras décadas del siglo XX. El joven Hurtado apuntó en 1918, mientras discernía su vocación religiosa, que una razón para entrar a los jesuitas era ayudar a «chilenizar la $\operatorname{cas} a\rangle^{12}$, expresión que debe haber escuchado de alguno de los jesuitas que frecuentaba. Esta preocupación dio sus frutos, pues durante los años veinte se produjo una

\footnotetext{
8 Ídem, 25.

9 Pío XI, Encíclica Ad Catholici Sacerdotii, 1935, no 61 y 62.

10 W. Bangert, A History of Society of Jesus (Saint Louis 1986) 433 y 500.

11 W. Ledochowski, Selected Writings of Father Ledochowski (Chicago 1945) 138. La traducción es mía.

12 [Primer discernimiento vocacional], [1918], APH s37y06.
} 
explosión de vocaciones chilenas. En 1906, la Misión Chile-Paraguay contaba con una mayoría de jesuitas españoles provenientes de la Provincia de Aragón; eran 96 repartidos entre Ancud, Puerto Montt, Concepción, Valparaíso y Santiago ${ }^{13}$. De acuerdo con los datos de la curia de la Compañía de Jesús en Chile, es posible observar que entre 1900 y 1909 solo once chilenos entraron a la Compañía de Jesús en Chile. Este número descendió a ocho en la siguiente década, mientras que entre 1920 y 1929 dio un salto a 101 vocaciones chilenas. En solo diez años el número de vocaciones locales aumentó diez veces. La década de los treinta no fue peor, 113 vocaciones chilenas, es decir, alrededor de diez por año. En este sentido, Alejandro Magnet, primer biógrafo de Hurtado, se equivoca cuando señala que en los once años de ausencia de Hurtado en Chile, habrían entrado a la Compañía solo «unos 25 chilenos no más» ${ }^{14}$.

No obstante estos números, el crecimiento de la población ${ }^{15}$ y el consiguiente incremento en las demandas pastorales mantuvieron a los jesuitas y a la Iglesia en general con la permanente sensación de falta de vocaciones.

\section{Un promotor de vocaciones encendido}

"Qué porvenir aguarda a nuestra patria si no se remedia este gravísimo problema», repetía el Padre Hurtado, los sacerdotes «qué pocos resultan para contrarrestar tamaña miseria material y moral $\rangle^{16}$. Muy probablemente como resultado del trabajo de la comisión creada por Llusá en 1936 y de las condiciones que mostraba Hurtado para el trabajo con jóvenes, un año más tarde se le confió especialmente a él la promoción de vocaciones ${ }^{17}$. El trabajo vocacional fue perfilándose así como uno de sus principales ministerios. Fue un trabajo que lo apasionó y que asumió con entusiasmo ${ }^{18}$. No le faltaban ideas ni energía.

\footnotetext{
13 M. Revuelta, La Compañia de Jesús en la España Contemporánea (Madrid 1991) 652.

14 A. Magnet, El Padre Hurtado (Santiago 2003) 133.

15 En Chile, la población creció de 3.220.531 habitantes en 1907 a 5.023.539 en 1940 (S. Correa y otros, Documentos del siglo XX chileno [Santiago 2001] 551).

16 [El problema social], [1936], APH s53y15b.

17 Carta del superior regional Pedro Alvarado al P. General, Wlodimir Ledóchowski, Santiago, 20 de febrero de 1937, en Archivo de la provincia chilena de la Compañía de Jesús 2/ H/ 420 carpeta 03.

18 Carta a Raúl Montes, [1937], APH s62y074.
} 
En febrero del año 1937, el Padre Hurtado predicó el retiro anual para el clero de Concepción; allí animó a los sacerdotes a asumir la tarea de reconstruir la sociedad. El problema de Chile es un problema de capellanes, les dijo, «aunque somos muy pocos, nuestra misión sacerdotal es ser sal: reflectores, directores... Tomarse el corazón con las dos manos y ser plenamente sacerdotes las

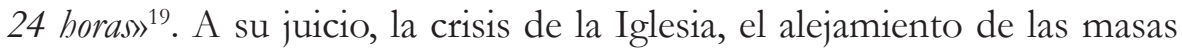
desde su seno, se debía en parte a la falta de santidad del sacerdote, que no estaba con el pobre, y que no era capaz de sacrificar su tiempo para acompañar a los jóvenes. Les echaba en cara que muchos sacerdotes vivían desengañados de su sacerdocio, muchos eran incapaces de preocuparse por las vocaciones y de fomentar la vida espiritual de su grey; por eso los animaba a dejarse seducir por Dios y vencer el pesimismo. Y les recomendaba un trabajo vocacional concreto: echen el ojo, les decía, fíjense en candidatos, tengan una preocupación constante hacia ellos, no tengan miedo en predicar directamente sobre el sacerdocio y la vocación, y déjense ayudar por revistas, libritos, estampas, incluso por hermanos o parientes; y les recordaba que no trabajasen solo por vocaciones diocesanas, sino también por las religiosas ${ }^{20}$.

Estos medios que Alberto Hurtado proponía fueron los mismos que él ocupó durante estos años. Su relación con los jóvenes era muy cercana y ellos sentían que él les prodigaba un genuino y cariñoso interés. Era distinto confesarse con él; aunque sus recomendaciones espirituales eran exigentes (comunión diaria, confesión semanal, lectura constante de la Biblia, rato personal de oración todos los días), los jóvenes se sentían desafiados a un heroísmo capaz de cambiar la sociedad ${ }^{21}$. Pese a que una y otra vez señalaba en sus cartas estar superado por el trabajo y las responsabilidades en aumento, les dedicaba tiempo precioso, «me tienen casi absorbido los universitarios», decía a un amigo ${ }^{22}$. Siempre había cola en su pieza, y a todos los atendía, «pero un poco más a los que pintaban para cura» ${ }^{23}$; en su pieza manejaba una biblioteca bien surtida, con un fichero, y nadie salía

\footnotetext{
19 Principio y Fundamento, [1937], APH s40y13.

20 Encarnación, [1937], APH s35y02.

21 Estas afirmaciones están tomadas de los testimonios recopilados en H. MonTES, Alberto Hurtado. Cómo lo Vimos (Santiago 1994) 16 (testimonio de Monseñor Carlos Camus), 53 (testimonio de Alfredo Matte Lira) y 64 (testimonio de Hugo Montes Brunet).

22 Carta a Raúl Montes, 1937, APH s62y062.

23 Testimonio de Luis Larraín, en H. Montes, Cómo lo Vimos, 40-41.
} 
de ahí sin un libro espiritual. No tenía miedo en presentar la vocación a sus acompañados. Su impulso hacia la acción entusiasmaba a los jóvenes, no solo la "gran fuerza de atracción de su natural simpatía y afabilidad»" ${ }^{24}$, sino su generosidad y el fuego de su celo apostólico. Ellos lo admiraban y querían ser como él ${ }^{25}$. Lo veían activo, capaz, seguro de sí y contento. Sabían que era un cura ocupado y que corría de un lado a otro, pero también sabían que no se negaría si le pedían conversar o visitar a un pariente enfermo.

\section{Un sacerdocio anclado en el pasado}

No se puede negar que Alberto Hurtado traía cierta novedad en la vivencia de su sacerdocio. Creía en la necesidad de un sacerdocio activo y conectado con el mundo y eso atraía a muchos: «Es indispensable que el sacerdote tenga más contacto con el pueblo: visite, vaya, se interese por problemas de cada uno. En Alemania y en Arica hasta los bailes.... ${ }^{26}$. Esto era novedoso, es cierto, sin embargo, al mismo tiempo estaba marcado con un fuerte acento clerical. Para él, esta iniciativa y conexión con el mundo, que debía caracterizar al sacerdote, era el medio fundamental para lograr el acercamiento de los alejados de la Iglesia y así superar la crisis de irrelevancia que la amenazaba. El sacerdote era el principal responsable del futuro de la Iglesia; él debía ser «como el director de orquesta que hace todo, sin hacer nada... ni sabe a veces tocar, piano, violín... apenas hace gestos [pero] sin él desconcierto, desafinadura $»^{27}$. El sacerdote era el principal educador y el guía, «nosotros sacerdotes tenemos la gracia de estado para interpretar las voces del Espiritu Santo en el fondo de las almas de los penitentes y para enderezarlas.... ${ }^{28}$. El sacerdocio era para Hurtado, pues, un gran ideal y la solución a los problemas sociales ${ }^{29}$ y vivía esta responsabilidad como una exigencia personal que le daba a su vida un tono urgente.

Pero esta idea heroica y ascética del sacerdocio estaba fuertemente anclada en una concepción tridentina del sacramento del orden y en una eclesiología previa al Concilio Vaticano II. Este esquema, que reaccionaba a las críticas protestantes al sacerdocio, enfatizaba la centralidad de

\footnotetext{
24 A. Lavín, El Padre Hurtado, Amigo y Apóstol de los Jóvenes (Santiago 1978) 7.

25 Testimonio de Alfredo Matte, en H. Montes, Cómo lo vimos, 57.

26 La vida parroquial, [1940], APH s40y12c.

27 Ibídem.

28 Aspirar a la santidad, [1939], APH s53y07.

29 Primera misa, [1938], APH s56y27.
} 
este como primer agente en la vida de la Iglesia. Los seminarios de los siglos siguientes a Trento promovieron la imagen del sacerdote como un «hombre aparte», separado del laicado y de la vida común de los cristianos ordinarios, y los seminaristas eran entrenados para mantener esta diferencia ${ }^{30}$. Las acciones fundamentales en la misión del sacerdote, como instrumento de Dios en la tierra, eran la celebración de la Eucaristía y la oración personal, y estas labores requerían sujetos bien formados, virtuosos y abnegados.

Habiendo recibido esta educación durante dos siglos, los sacerdotes arribaron al siglo XIX como figuras de respeto y honor en la sociedad. Tener un sacerdote en la familia era motivo de prestigio y orgullo y la vocación sacerdotal era no rara vez animada e impulsada por parientes y amigos. El modelo del sacerdote estaba marcado por virtudes como la piedad, la docilidad y un fuerte autocontrol; la vida en los seminarios y en las casas de formación de religiosos observaba estrictamente una serie de reglas destinadas a desarrollar estas virtudes. El rechazo del mundo tuvo un lugar prevalente en este modelo; los seminarios eran construidos siempre mirando hacia dentro y tratando de mantener alejados a los seminaristas del mundo. La tradición tridentina marcó escrupulosamente la diferencia entre lo sagrado y lo profano, y por tanto, era mal visto que los sacerdotes se vieran envueltos en actividades o negocios mundanos, como deportes, juegos, o entrando a cafés o tiendas; el mundo debía entenderse como un lugar hostil y extraño para el clero. En consonancia con eso, el cuerpo era uno de los principales enemigos que un sacerdote podía tener y del cual había que cuidarse con virtud y abnegación. En este sentido, la modernidad trajo todo aquello que este modelo de sacerdote debía rechazar ${ }^{31}$.

Como resultado de esta evolución, los sacerdotes de la primera mitad del siglo XX vivían su ministerio centrados en la Iglesia más que en la sociedad, su horario se organizaba de acuerdo con la celebración de la Eucaristía y la oración del breviario. El enfoque clerical era profundizado por los manuales de teología que repetían mecánicamente la enseñanza de Santo Tomás de Aquino. Algunos sacerdotes intentaron penetrar en diversas áreas de apostolado más allá de la administración de los sacra-

30 K. Osborne, «Priestly Formation», en R. Bulman - F. Parrelda (eds), From Trent to Vatican II. Historical and Theological Investigations (New York 2006) 124.

31 R. Gibson, A Social History of French Catholicism 1789-1914 (New York 1989) 90-92. 
mentos, como la educación, el trabajo con la juventud o los obreros. Urgidos por la defensa de la Iglesia frente al avance de la secularización, unos pocos, con mejor formación y roce, entraron a trabajar en escuelas públicas, revistas Católicas, partidos políticos y otras actividades seculares ${ }^{32}$, sin embargo, hasta bien entrado el siglo XX no fue esta la norma.

Los cambios en la sociedad, la cultura y la teología, hicieron fuerte mella en esta concepción ascética y clerical del sacerdocio. Cada vez mejor educados y con nuevas preguntas, los laicos comenzaron a ocupar, lenta y progresivamente, un nuevo lugar en la Iglesia. Alberto Hurtado vivió en carne propia esos cambios. La concepción tradicional en la que había descubierto su propia vocación, en la que había sido formado y la que proyectaba a los jóvenes, comenzaba a trizarse; un nuevo modo de ser Iglesia y de mirar la sociedad estaba en plena gestación hacia el Concilio Vaticano II. Esta transición traería giros en el foco de su vida y su misión.

\section{Un Especialista en Jóvenes. Ministerio entre 1941 y 1944}

\section{Asesor de la Acción Católica}

Ya en noviembre de 1938, dirigentes de la Acción Católica habían solicitado al viceprovincial, Pedro Alvarado, que permitiera al Padre Hurtado ser el nuevo asesor de la rama de hombres. Sin embargo, la respuesta había sido negativa atendida la sobrecarga y la importancia de los trabajos que Hurtado estaba emprendiendo ${ }^{33}$. Un par de años después, a principios de 1941, el recién nombrado Asesor Nacional de la Acción Católica y obispo auxiliar de Santiago, monseñor Augusto Salinas, fue a la carga de nuevo y logró que la Compañía liberara a su íntimo amigo para el cargo de Asesor Arquidiocesano de la rama juvenil de la Acción Católica. A decir verdad, no se le liberó demasiado; en lo principal, siguió haciendo lo mismo en el Colegio San Ignacio, salvo las Congregaciones Marianas, que dejó en manos de otro jesuita ${ }^{34}$; continuó con las clases en la Universidad Católica, ese año a los alumnos de Derecho, y con la dirección de la casa de ejercicios de Loyola. Pocos meses más tarde, en julio de 1941, tras negociaciones con el Arzobispo, Cardenal José María Caro, y contra el parecer de

32 K. Osborne, Priesthood: A History of Ordained Ministry in the Roman Catholic Church (Oregon 1989) 292.

33 Libro de la Consulta de la viceprovincia chilena de la Compañía de Jesús, Santiago, noviembre 20, 1938, p. 192.

34 Catálogo de Alumnos del Colegio San Ignacio, Santiago, 1941, p. 3. 
su consulta ${ }^{35}$, el viceprovincial aceptó que además lo nombraran Asesor Nacional de la Juventud de la Acción Católica.

Si Alberto Hurtado estaba ya dedicado a los jóvenes, esto significó un impulso aun más poderoso en su «especialización». Hurtado se propuso sacar lo mejor de los jóvenes, ser un guía en medio de la «desorientación profunda del alma contemporánea» y ayudarlos a comprender cómo la fe en Cristo -la religión- era «algo básico, un recto juicio del mundo, una vida y un amon $\rangle^{36}$. Así como había visto el entusiasmo en los movimientos juveniles de Europa de principios de los treinta, especialmente la Nueva Alemania y las Juventudes Obreras, quería animar a los jóvenes a emprender la lucha contra el avance de la increencia y los antivalores paganos ${ }^{37}$.

\section{La Acción Católica, un llamado a la recristianización de la sociedad}

El Padre Hurtado calzó de inmediato en la horma de la Acción Católica. Su preocupación ante la descristianización de la sociedad enganchaba perfectamente con el llamado de la Iglesia Católica a todos los cristianos a trabajar activamente en la propagación y restauración del Reino de Cristo a través de la Acción Católica ${ }^{38}$. Como se ha señalado, el avance de la secularización y los sucesivos conflictos sociales y políticos, habían urgido a una reacción por parte de la Iglesia Católica universal. En Chile, la Iglesia fue parte de ese movimiento desde sus inicios. Durante el siglo XIX, el clero y el laicado chilenos habían adoptado el modelo ultramontano, estableciendo fuertes vínculos con la Santa Sede, a pesar de la distancia y la dificultad en las comunicaciones, y defendiendo a brazo partido el «orden católico» de la sociedad chilena ${ }^{39}$. A lo largo del siglo XIX, la jerarquía chilena se había esforzado por mantener el catolicismo de la nueva república y había organizado su defensa creando una importante estructura de instituciones de educación, medios de comunicación y asistencia al pobre. De este modo, el avance de la secularización de la sociedad chilena no significó un decaimiento en la vivencia del catolicismo, ya que la Iglesia «readecuó

35 Libro de la Consulta, mayo 26, 1941, p. 14.

36 El educador del espíritu, [1941], APH s20y15.

37 A. Hurtado, «Una nueva juventud», Estudios, marzo (1938) 13-27; A. Hurtado, ¿Es Chile un país católico? (Santiago 1941) 30 y 37.

38 E. Iserloh, «Movements within the Church and their Spirituality» en H. Jedin (ed.), The Church in the Modern World (New York 1993) 875.

39 F. Aliaga, La Iglesia en Chile. Contexto Histórico (Santiago 1989) 133-146. 
sus asociaciones tradicionales a la nuevas condiciones y combatió la secularización con instrumentos modernos, afianzando su presencia en la sociedad civili ${ }^{40}$.

Durante las dos primeras décadas del siglo XX, la Iglesia en Chile mantuvo la postura defensiva y anti-liberal que caracterizó a la Iglesia universal. Con su orientación neo-tomista y ultramontana, el seminario de Santiago llegó a ser un importante centro cultural del país y, en sintonía con los demás seminarios (La Serena, Valparaíso, Talca, Concepción y Ancud), formó un «clero culto y de gran ascendiente moraly sociab $\rangle^{41}$. La Universidad Católica, que había sido fundada en 1889 para tamizar la influencia laicizante de la Universidad de Chile, recibió un nuevo impulso con dos activos rectores, los presbíteros Martín Rucker y Carlos Casanueva ${ }^{42}$. En 1915, fue fundada la ANEC, por el presbítero Julio Restat, para organizar a los estudiantes universitarios católicos y tratar de influir en la sociedad a través de jóvenes «elegidos»; la ANEC promovió los Círculos de Estudios, especialmente en materias sociales, y publicó una revista con la que entusiasmó a muchos jóvenes en sus actividades espirituales y de asistencia social ${ }^{43}$. Durante este tiempo, la formación pastoral tuvo un objetivo apologético, preparaba al católico para discutir y vencer al protestante, al socialista y al laicista; los jóvenes debían estar prontos a defender su fe en las calles y se organizaban encuentros masivos, como los Congresos Eucarísticos y los Congresos Marianos, para promover la devoción a la Eucaristía, al Sagrado Corazón y a la Virgen ${ }^{44}$.

Asumida como modelo para toda la Iglesia por el Papa Pío XI ${ }^{45}$, la Acción Católica trajo un espíritu de renovación ${ }^{46}$. Influidos por Jacques Maritain, Columba Marmion y Émile Mersch, los católicos comenzaron a soñar con una «Nueva Cristiandad», la sociedad podía volver a ser cristiana nuevamente ${ }^{47}$. Esta actitud idealista inspiró un despertar en la teología

40 S. Serrano, ¿Qué hacer con Dios en la República? Política y Secularización en Chile (18451885) (Santiago 2008) 168.

41 F. Aliaga, La Iglesia en Chile, 166.

42 F. Araneda, Historia de la Iglesia en Chile (Santiago 1986), 721. Ver también F. Aliaga, La Iglesia en Chile, 167.

43 F. Aliaga, La Iglesia en Chile, 178.

44 Ídem, 178-184.

45 Pío XI, Encíclica Ubi Arcano Dei, 23 de diciembre de 1922.

46 E. IserLoH, «Movements within the Church and their Spirituality», 875.

47 E. Dussel, Historia de la Iglesia en América Latina. Medio milenio de coloniaje y liberación (1492-1992) (Madrid 1992) 179-180. 
y en la pastoral. La teología del Cuerpo Místico de Cristo, que fue muy importante para Hurtado ${ }^{48}$, inauguró un nuevo modo de comprensión de la Iglesia, menos centrado en sí misma como sociedad perfecta, y más cristocéntrica. Según esta teología, Cristo con su muerte y resurrección no se alejó del mundo, sino que penetró más profundamente en él, convirtiéndose en corazón de la humanidad y fermento de la historia; el cristiano, entonces, estaba llamado a participar en la misma vida de Cristo, ser un miembro de Él comprometido con la suerte del mundo ${ }^{49}$. Esta concepción fue recogida por la Acción Católica y refrescó la pastoral, pues animó a los laicos a participar activamente en el apostolado de la Iglesia; la responsabilidad de la edificación eclesial ya no recaía exclusivamente sobre los sacerdotes y religiosos, que eran solo una parte de Cuerpo de Cristo, sino sobre el conjunto de los cristianos. El laico fue encontrando así un lugar en la restauración de la Iglesia y la renovación de la sociedad. Unido a esto, la encíclica Quadragesimo Anno generó la expectativa de un nuevo orden cristiano capaz de «reconquistar el mundo». Los católicos se sintieron invitados desde su propio lugar de trabajo y oficio a abogar por la transformación social del ambiente y presentar el cristianismo como una solución plausible a la crisis económica y social que vivía el mundo.

\section{Las vocaciones, el más grave de los problemas}

El inicio de la Segunda Guerra Mundial amenazó gravemente esta esperanza que la generación de los treinta había enarbolado. Para muchos, la guerra no era sino la expresión de una crisis de fondo y ahogaba las ingenuas ilusiones de los optimistas sobre el futuro del mundo. Cundía la desazón, y el Padre Hurtado transmitía el sinsentido que se respiraba frente la guerra, "kilómetros y kilómetros yacen cubiertos de ruinas con millones de cadáveres insepultos, [el equivalente a] la población entera de Chile ha muerto ya en estos dos años de guerra.... ${ }^{50}$. La denuncia de la crisis social y moral de la sociedad moderna se agudizó en él durante este período, y con ella su clamor por más vocaciones al sacerdocio. «iPor qué no decirlo?, escribía Hurtado en la revista de Aspirantes de la Acción Católica, «ligereźa, superficialidad,

48 Sobre la relación entre la teología del Cuerpo Místico y el Padre Hurtado ver F. PARRA, «Teología del Cuerpo Místico, Comunión de los Santos y pensamiento social en san Alberto Hurtado. La influencia de Émile Mersch y Karl Adam» en Teología y Vida L (2009): 797-835.

49 J. Castellón, Padre Alberto Hurtado, Su Espiritualidad (Santiago 1998), 25.

50 Vos estis sal terrae, [1941], APH s56y14. 
inconsciencia, falta de esfuerzo, ansia de diversiones, de vida fácil y cómoda, vienen minando las energias espirituales de nuestra raza. Un ansia de placer parece dominarlo todo; una falta absoluta de responsabilidad, de sentido patriótico, de espiritu de sacrificio y de comprensión, se ha apoderado de muchisimos de nuestros conciudadanos ${ }^{51}$. Su predicación encontró en este desolador contexto su caja de resonancia; su invitación era radical a no desentenderse de la «borrenda guerra en que estamos sumidos $^{52}$, y a no ser meros espectadores de la crisis mundial: «Si ese sufrimiento es real no podemos contentarnos con la posición de los concurrentes al teatro, sino que hemos de obrar conforme a la verdad de nuestros sentimientos. ¿Hay menos fiestas, menos comidas lujosas, menos diversiones en estos momentos de dolor? $\rangle^{53}$.

La Acción Católica había sido creada precisamente para hacer frente a esta crisis. Y el Padre Hurtado vio en ella el medio apropiado para «la recristianización del individuo y de la sociedad... [para] hacer cristiana a la sociedad $y$ hacer cristiano, profundamente cristiano, al individuos ${ }^{54}$. Por eso, en una sociedad que había «perdido el sentido de lo divino» ${ }^{55}$ era necesario que la Acción Católica abordase el problema más grave y urgente de todos, la falta de sacerdotes ${ }^{56}$ : «El más grave problema religioso nacional, la crisis sacerdotal, la Acción Católica juvenil esperamos que en Chile la ha de solucionar dando muchos, los mejores de los jóvenes al servicio total de la Iglesia» ${ }^{57}$. A su juicio, «toda la vida cristiana está llena del sacerdote, y todos debieran interesarse porque su número sea cada vez. mayon ${ }^{58}$; el sacerdote era el dique frente a la degradación moral, de la cual la Segunda Guerra Mundial no era sino el fruto: «Si esos valores desaparecen la sociedad se hunde en las mayores atrocidades y crimenes; y el sacerdote es el hombre que consagra su vida a la misión heroica de recordar en todo instante a la humanidad el sentido de esos valores.... ${ }^{59}$. Como hemos dicho, su visión del sacerdocio no era solo heroica, sino fuertemente ascética: «El mundo moderno está perdido

51 A. Hurtado, «A Revisar las Tropas», Canta y Avanza 5 (julio 1942) (A revistar las tropas, 1942, APH s19y25).

52 Ibídem.

53 Asamblea del Alcázar, [1943], APH s19y14.

54 El campo de trabajo de la Acción Católica, [1942], APH s19y05.

55 S. Fernández (ed.), Un Disparo a la Eternidad. Retiros Espirituales predicados por el Padre Alberto Hurtado, SJ (Santiago 2004) 172.

56 A. Hurtado, ¿Es Chile un país católico?, 128.

57 Fariseo y Publicano, [1943], APH s54y19.

58 S. Fernández (ed.), La Búsqueda de Dios. Conferencias, Artículos y Discursos Pastorales del Padre Alberto Hurtado, SJ (Santiago 2005) 247.

59 Vos estis sal terrae, [1941], APH s56y14. 
porque busca las concupiscencias: dinero, placer, honra, libertad, mando, poderío... y el sacerdote que es de veras sacerdote da el sublime ejemplo de renunciar a todo eso en el momento mismo en que más podría halagarle» ${ }^{60}$.

Este convencimiento sobre la radical importancia del sacerdote en la recristianización de la sociedad llevó al Padre Hurtado a escribir tres libros durante este período con un manifiesto y enérgico contenido vocacional. ¿Es Chile un país católico? remeció la escena chilena presentando una autocrítica feroz a la Iglesia y las consecuencias de la vivencia de un cristianismo superficial. El libro no pasó desapercibido y levantó polémica ${ }^{61}$. En el prólogo de una segunda edición, que finalmente Hurtado nunca publicó, dejó claro que su libro era un «un llamado sacerdotal a los jóvenes invitándolos a mirar la realidad religiosa de su Patria y a darse enteros a la causa de Criston, porque «la mayor parte de los jóvenes que hemos conocido personalmente que han entrado al Seminario o a un Noviciado lo han hecho porque han adquirido conciencia de su responsabilidad cristiana ante la crisis religiosa de su Patrias ${ }^{62}$.

Un año más tarde, en 1942, Hurtado publicó Puntos de Educación, donde, sin faltarle también polémica ${ }^{63}$, presentó un conjunto de temas y una metodología de formación para los jóvenes de la Acción Católica. Dos de sus capítulos abordaron explícitamente la crisis sacerdotal. Si en ¿Es Chile un país católico? señalaba que «el más grave de los problemas» era la escasez de sacerdotes $^{64}$, en Puntos de Educación, el más grave era la falta de educación ${ }^{65}$; sin embargo, no se trató aquí de una incoherencia de su parte, sino de una concreción de su visión sobre la centralidad del sacerdote, pues este, a su juicio, era el educador por excelencia y si faltaba, la educación sufría gravemente: «El porvenir de nuestra educación cristiana, y más aún, de la misma Iglesia Católica en Chile está intimamente ligado a la solución de la crisis sacerdotal, [...] el mejor índice para jusgar de la vitalidad del catolicismo en una Nación es el número y fervor de su clero» ${ }^{66}$.

60 Ibídem.

61 Sobre esta polémica, ver P. EsPINOSA, «¿Es Chile un país católico? Polémica en torno a un libro del Padre Hurtado», Teología y Vida, XLVI (2005) 625-674; A. Magnet, El Padre Hurtado, 181.

62 Una palabra al lector, [1942], APH s53y25.

63 Ver Acción Católica y Política, [1942], APH s20y30 y Carta a Agustín Zegers, 1942, APH s64y17.

64 A. Hurtado, ¿Es Chile un país católico?, 128.

65 A. Hurtado, Puntos de Educación, p. 20.

66 Ídem, p. 167. 
En el tercer libro de este período, el Padre Hurtado abordó el tema vocacional de modo aun más explícito. Elección de Carrera, escrito en 1943, sintetizó en cierta manera lo que había venido predicando a los jóvenes desde su llegada a Chile. Hurtado leyó agudamente su época y propuso a los jóvenes aquello que percibió que en la cultura estaba siendo flaco y que necesitaba ser reforzado en pos de un cristianismo capaz de superar la crisis del mundo. Frente a la esperanza moderna en el progreso y el desarrollo inmanente del ser humano, Hurtado propuso el cielo y la eternidad; el joven debía mirar hacia su fin trascendente a la hora de tomar sus decisiones y considerar la vida en su aspecto «sobrenatural», como un viaje hacia la eternidad. Frente al modo de vida contemporáneo, cuyo eje estaba puesto en el individuo, su confort y su propio placer, Hurtado apeló al sacrificio por un ideal alto, un ideal que estaba más allá del sujeto. Alberto Hurtado era un hombre moderno, valoraba al sujeto, pero lo subordinaba al bien del «Cuerpo Místico de Cristo» ${ }^{67}$; por eso enfatizaba que Dios se dirigía personalmente a cada joven, y que este debía descubrir sus cualidades y aptitudes personales para ponerlas siempre al servicio de Cristo y los demás; las motivaciones y deseos de individuo eran claves, pero había que darles un norte, una dirección trascendente. Si el placer y la vida fácil eran modelos que colmaban la publicidad y el cine, Hurtado propuso la abnegación, la fuerza de voluntad y la pureza sexual como herramientas imprescindibles. Frente al ruido y el movimiento constante de las sociedades modernas, su enseñanza se detuvo en el cultivo de la vida interior, la oración y el examen. La presentación de las reglas de discernimiento de San Ignacio, que hace Elección de Carrera, está constantemente atravesada por este contrapunto con la modernidad.

\section{Laicos: llegar donde el sacerdote no puede}

A pesar de su constante preocupación por las vocaciones sacerdotales, el trabajo con los jóvenes en la Acción Católica puso una cuña en su concepción clerical de Iglesia. Este discurso tan centrado en el sacerdote como solución, comenzó a convivir con aquel fundado en la novedad que la Acción Católica trajo a la Iglesia de la primera mitad del siglo XX: los sacerdotes necesitan la colaboración del laicado para cumplir su misión. Así el Padre Hurtado, ante la escasez de sacerdotes, empezó a llamar a los jóvenes no solo al sacerdocio, sino también a «llegar donde el sacerdote no puede llegan», a ser colaboradores de Cristo en una «obra que

\footnotetext{
67 A. Hurtado, Elección de Carrera (Santiago 1955) 28.
} 
solo tú puedes hacen ${ }^{68}$. De este modo, invirtió su esfuerzo y esperanza en la formación de grupos de elite, colaboradores formados y comprometidos que participaran de la misión de la jerarquía «sin llevar sotana ${ }^{69}$; la vida del laico, si era verdaderamente cristiana, podía llegar a ser también instrumento de recristianización. En un retiro a sacerdotes decía, «el método de la Acción Católica es substancialmente la formación de un grupo escogido de almas de selección que se llenen de Cristo, se chiflen por Cristo y mediante ellos, que estarán tomados de todos los medios -en grupos especializados- vengamos a reintegrar a la vida de la Iglesia a todos los fieles en una vida cristiana de convicción y de acción $\rangle^{70}$. E insistía en que había que dar responsabilidades a los jóvenes y que «el cura no lo haga todo» ${ }^{71}$.

En la retórica y acción del Padre Hurtado, estos dos discursos -la necesidad imperiosa de sacerdotes y la valoración de la colaboración laicalcorrieron en paralelo, a veces complementarios, a veces contradictorios; sin embargo, como veremos más adelante, poco a poco los acontecimientos de su vida le ayudarían a sintonizar más finamente con los signos de los tiempos que corrían: la misión de la Iglesia es también la misión de los laicos.

\section{Un giro inesperado pero largamente incubado}

El discurso social de Alberto Hurtado fue transversal a todos sus años de ministerio, sin embargo, el año 1944 se hizo particularmente más recurrente y punzante que los años anteriores. En conferencias, homilías y retiros apeló a la conciencia social de sus auditores, «la injusticia causa enormemente más males que los que puede remediar la caridad... No sucumbamos a los encantos de una caridad mal entendida que desprecia a su sencilla y bumilde hermana, la justicia ${ }^{72}$. A los jóvenes los instó con especial ardor a preocuparse de los hermanos más pobres, porque ser católicos era ser sociales y desamparar al hermano era desamparar a Cristo mismo. La recristianización de Chile implicaba no solo la formación cristiana -seria y profunda-, no solo la incorporación de nuevos sacerdotes -tarea urgente-, sino la lucha contra

\footnotetext{
68 Las 3 conquistas de la Acción Católica, [1941], APH s19y09.

69 El campo de trabajo de la Acción Católica, [1942], APH s19y05.

70 Ibídem.

71 Buscar colaboradores, [1942], APH s56y12a.

72 La virtud de la justicia, [1944], APH s46y09.
} 
la injusticia y la miseria de los hermanos ${ }^{73}$. En febrero de 1944, dando retiro a un grupo de jesuitas, los invitó a considerar las razones para orar sobre la justicia: «1 $1^{\circ}$ porque el Señor nos pide tener hambre y sed, pasión rabiosa... $2^{\circ}$ porque el mundo moderno perece por falta de justicia y esta falta está tramando una gran revolución ${ }^{74}$.

Este discurso social se vio potenciado y encauzado por tres acontecimientos cruciales en la vida de Alberto Hurtado. El primero fue la visita de uno de sus profesores de Teología en Lovaina. En octubre de 1943, el Padre Pedro Charles, S.J., experto en misionología, llegó a Chile, tras un largo periplo alrededor del mundo dando conferencias, retiros y cur$\operatorname{sos}^{75}$. Charles había impresionado a Hurtado ya en Lovaina, sin embargo, esta visita a Chile lo marcó hondamente y lo reconectó con mucho de lo que había asimilado en su formación en Bélgica. Charles dio un retiro a jesuitas a finales de febrero de 1944 y Hurtado tomó abundante nota de sus charlas y lo que ellas le generaron. La fineza espiritual de Charles tocó a Hurtado especialmente en aquello que venía rumiando. Se fascinó con la imagen que traía Charles de una Iglesia interesada por los asuntos y angustias del mundo y de un sacerdote ordenado no para las ideas, sino para el servicio del pueblo, una Iglesia misionera que no solo bautiza y hace catequesis, sino que atiende todas las necesidades de sus fieles. La idea de Charles sobre la colaboración enganchó particularmente en el temple ignaciano de Hurtado, el Señor está en todas partes obrando y necesita de la colaboración de cada cristiano, la Encarnación supone la aceptación personal, el Reino se construye por la generosidad y la misión particular de cada uno ${ }^{76}$. Hurtado repetiría estas ideas hasta el final de sus días.

El segundo hecho clave fue el conflicto con Monseñor Augusto Salinas, que terminó con su salida de la Acción Católica. El conflicto se fue urdiendo lentamente; ya en 1942, Hurtado había presentado una primera renuncia porque sentía que su criterio no estaba en sintonía con el de la

73 El deber de la Caridad, 1944, APH s54y27; [Semana de Estudios Sociales], [1944], APH s19y32; [Discurso en el Caupolicán], 1943, APH s19y27; Caridad, [1944], APH s51y18a.

74 La caridad, [1944], APH s51y15.

75 El Padre Charles con nosotros, 1943, APH s71y023.

76 S. Fernández (ed.), Un disparo a la Eternidad, 125-143; Ejercicios Padre Charles, [1944], APH s39y06b. 
Comisión Episcopal a cargo de la Acción Católica ${ }^{77}$. Hurtado y Salinas fueron amigos desde la época universitaria, sin embargo, sus relaciones se fueron haciendo cada vez más tensas estos años. El quiebre entre ambos amigos tuvo un origen complejo, se mezclaron discrepancias políticas, diferencias de carácter y desconfianzas mutuas acerca de los criterios en la conducción de los jóvenes católicos. Lo cierto es que, cansado y dolido, el Padre Hurtado presentó, en noviembre de 1944, su renuncia definitiva a la Acción Católica ${ }^{78}$. Está renuncia significó para Alberto Hurtado el comienzo de un alejamiento progresivo del mundo de los jóvenes.

La fundación del Hogar de Cristo fue el tercer acontecimiento que cambió la vida de Hurtado. En cosa de pocas semanas, dejó la Acción Católica y fundó la institución de asistencia social que le daría fama y renombre en la sociedad chilena. El Padre Hurtado experimentó de cerca el sufrimiento del indigente y vio en su rostro el rostro de Dios; sintió la necesidad de ser coherente con su discurso social y hacer algo frente a la realidad que la mayoría de la sociedad chilena quería evadir. Esto provocó un vuelco en su acción y en su comprensión del lugar de la Iglesia en el mundo moderno. Asimismo, lo que había venido germinando en el trabajo codo a codo con los jóvenes en la Acción Católica se cimentó con la fundación del Hogar de Cristo: una valoración distinta del papel de los laicos en la Iglesia. Hurtado comprendió, a poco andar, que sin la colaboración de los laicos no había tarea en la Iglesia que pudiese ser emprendida y sostenida en el tiempo. Así comenzaría una nueva etapa en la vida de Alberto Hurtado.

\section{Los Pobres como Lugar de la Iglesia. Ministerio entre 1945 y 1952}

\section{El dolor ajeno como propio}

El Padre Hurtado venía denunciando la escandalosa brecha entre ricos y pobres desde que volvió a Chile en 1936, sin embargo, como dijimos, estos años su discurso se hizo más urgente. En 1945, denunció que más de cinco mil mendigos recorrían las calles de Santiago y que la desnutrición era tan generalizada que incluso «la talla media del conscripto ha bajado ${ }^{79}$. La malnutrición fue un problema grueso hasta bien avanzado el siglo XX en

\footnotetext{
77 S. Fernández (ed.), Cartas e Informes del Padre Alberto Hurtado, SJ (Santiago 2003) 117-119.

78 Ídem, 120-131.

79 S. Fernández (ed.), La búsqueda de Dios, 106.
} 
Chile; en los años sesenta, todavía la mayoría de las familias de la capital vivía con menos de dos mil calorías al día ${ }^{80}$. La cesantía y la falta de modernización del agro chileno habían obligado a los habitantes del campo a desplazarse hacia las ciudades. En los años cuarenta, Chile era ya una nación urbana, la mayoría de la población vivía en ciudades de más de veinte mil habitantes. Pero la vida en la ciudad fue siempre una promesa incumplida para la mayoría de sus moradores. Autos, radios, teléfonos, muebles, agua potable y artículos de higiene, eran «posesiones sólo del rico... Chile es una tierra de descontento y malestan», escribía el decano de la facultad de Teología de la Universidad Católica, Gustav Weigel ${ }^{81}$. Un tercio de la población de Santiago vivía en condiciones infrahumanas en poblaciones callampas, conventillos o en casonas arrendadas por varias familias. No solo el hacinamiento y la falta de agua, luz y alcantarillado delineaban su precariedad, sino la ausencia total de un equipamiento educacional, de salud y de recreación mínimo ${ }^{82}$.

Este panorama caló hondo en Alberto Hurtado. En septiembre de 1944, había muerto Miguel Ángel, su hermano menor. Poco se conoce de él, pero fue una figura problemática y que preocupó siempre al Padre Hurtado $^{83}$. Su repentina muerte a los 41 años se unía a la temprana muerte de su padre y a la de su madre, siete años antes; debió ser un duro golpe para Alberto Hurtado, «cada vez, se va sintiendo uno más solo aquí: a ti como a mí se nos ha deshecho el nido chico», le comentó años después a un joven que había perdido a su padre ${ }^{84}$. Este hecho y, como se señaló al final del capítulo pasado, la predicación del Padre Charles, el quiebre en la Acción Católica y la fundación del Hogar de Cristo, eventos ocurridos todos en 1944, pusieron al Padre Hurtado en una especial situación de vulnerabilidad ante el sufrimiento humano que transformaría su vida. Hurtado experimentó «en lo vivo el dolor ajeno como propio» ${ }^{85}$ y lo hizo replantear su misión personal

80 S. Collier - W. Sater, A History of Chile, 1808-2002 (Cambridge 2004) 290.

81 G. Weiget, «The Chilean Popular Front» en Gustav Weigel Collection, Box 1 Folder 79, Georgetown University Library, Special Collections Division, Washington, D.C. La traducción es mía.

82 A. De Ramón, Santiago de Chile (1541-1991). Historia de una Sociedad Urbana (Santiago 2000) 242.

83 Ver S. Fernández (ed.), Cartas e Informes, 38 y 41.

84 Carta a Julio Silva, [1952], APH s70y098.

85 S. FERnÁndeZ, «Circunstancias de la fundación del Hogar de Cristo. Estudio histórico de los documentos contemporáneos», Teología y Vida IL (2008) 875-891. 
y la misión de la Iglesia en el mundo moderno. Comenzó a experimentar poco a poco un distanciamiento del mundo juvenil y una necesidad apremiante de estar más cerca de los desfavorecidos de la sociedad. Presentó otra vez, entre 1945 y 1950, a sus superiores los frutos de su oración y discernimiento que lo empujaban a la acción social y el compromiso con los obreros y los más pobres. Aunque notó desgaste en su interacción con el «elemento juvenil»» $»^{86}$, su preocupación por las vocaciones sacerdotales permaneció presente. Estos años, sin embargo, su ministerio vocacional se vinculó con su convicción sobre el lugar de la Iglesia en el mundo moderno: habrá más sacerdotes mientras más conectada esté la Iglesia con el mundo, sus anhelos y sus miserias.

\section{El tronar de los signos de los tiempos}

Alberto Hurtado tenía una sensibilidad especial para captar lo que estaba sucediendo en su ambiente. Observando los procesos sociales y las inquietudes de la gente, se daba cuenta de que la fe se hacía cada día más irrelevante en el concierto público y privado, la Iglesia no tenía el mismo arrastre en la masa, que se descristianizaba cada vez más; los católicos chilenos vivían un catolicismo formal que poco aportaba en la solución de los problemas urgentes del país. Una de las frases más citadas por el Padre Hurtado fue la que expresó Pío XI al canónico Cardijn, fundador de la JOC, «el gran escándalo del siglo XX es que la Iglesia haya perdido la clase obrera $\rangle^{87}$. Como se ha señalado, en el ideario de Hurtado las vocaciones sacerdotales eran la solución privilegiada frente a este avance de la secularización. Los sacerdotes eran los principales agentes de cambio, el medio para recuperar la tutela religiosa de la sociedad. Sin embargo, en su sintonía con los signos de los tiempos, estos años Hurtado comienza a relativizar esta convicción.

La Segunda Guerra Mundial había sido una dramática experiencia para toda la humanidad. Ansiedad, temor y una brutal desilusión contaminaron la atmósfera. La Primera Guerra Mundial y la depresión del 29 habían cuestionado profundamente el modelo capitalista y los ideales modernos de progreso y racionalidad; la Segunda Guerra Mundial ahondó estos cuestionamientos. La literatura y la filosofía de esos años daban cuenta de la ansiedad y el desencanto; Sartre, Camus, Beauvoir alcanzaron fama

\footnotetext{
86 Carta a Álvaro Lavín, 1947, APH s62y101.

87 A. Hurtado, ¿Es Chile un país católico? 15.
} 
con su existencialista y feroz descripción de la sociedad y la condición humana. La expansión del comunismo y los afanes imperialistas de la Unión Soviética amenazaron la frágil paz obtenida tras los bombardeos nucleares a Hiroshima y Nagasaki; la posibilidad de un desastre atómico comenzó a desvelar tanto a grandes políticos como a pobres campesinos alrededor del mundo. Profundos cambios estaban tomando lugar en el mundo en la mitad del siglo $\mathrm{XX}^{88}$.

Este conflictivo contexto preparó a la Iglesia para el Concilio Vaticano II. La experiencia de Hitler y Mussolini convenció finalmente a las autoridades eclesiales de la necesidad de reconocer, por primera vez, la democracia como el más deseable sistema político para el mundo moderno ${ }^{89}$; la amenaza del comunismo y su política de destierro de la religión presionó a los católicos a aceptar la libertad religiosa como un derecho inherente a cada sociedad; la conciencia del holocausto judío movió a la Iglesia a reconocer el valor y la legitimidad de otras religiones, más allá de su temor al indiferentismo religioso. Estos acontecimientos condujeron progresivamente a la Iglesia Católica a un cambio en su postura de rechazo al mundo moderno y a un «intento de tomar seriamente las ansiedades y preocupaciones contemporáneas de la bumanidads ${ }^{90}$. El Concilio Vaticano II ya no se veía lejos en el horizonte.

La teología y la pastoral se renovaron durante la primera mitad del siglo XX con una serie de movimientos que reaccionaron al secularismo ambiental. En un esfuerzo por reencantar a los católicos, el movimiento litúrgico apuntó a hacer el culto más fácil para las personas, privilegiando la experiencia de la Iglesia como comunidad y la participación en la liturgia a través de cantos y pequeños misales; Pío X promovió la comunión frecuente y la misa tendió a ser menos una «presentación teatral» y más una celebración inclusiva del sacrificio de Cristo. El movimiento bíblico, por otra parte, estuvo íntimamente ligado a la piedad cristocéntrica que se despertó durante este período; los católicos tuvieron más acceso a los Evangelios, a través de buenas traducciones a lenguas vernáculas, y circularon contundentes vidas de Cristo de autores como Lagrange, Grandmaison, Lebreton, Adam y Guardini. En los años cuarenta, la teología tomó

\footnotetext{
88 J. O’Malley, What Happened at Vatican II (Cambridge 2008) 90.

89 Pío XII, Radiomensaje Benignitas et Humanitas, diciembre 24, 1944.

90 S. Schloesser, «Against Forgetting: Memory, History and Vatican II» en D. SchulTENOver (ed.), Vatican II. Did Anything Happen? (New York 2008) 122. La traducción es mía.
} 
un nuevo impulso con el surgimiento de la Nowvelle Théologie. Esta teología propuso un tránsito desde una visión estática e inmutable del mundo hacia un esquema más histórico, más comprometido con una idea de desarrollo y más abierta a los cambios y a la subjetividad. Precisamente ella nació como una reacción a la «teología romana», caracterizada por métodos no históricos y un acercamiento más jurídico. La Nowvelle Théologie abrió la teología al existencialismo y a la fenomenología y, tomando los avances en la teología bíblica, patrística y litúrgica, propuso una reconciliación con el mundo moderno. Teólogos como De Lubac, Congar, Chenu, Rahner, Mersch, Chardin, lideraron este movimiento; sin embargo, esta teología no tendría plena aceptación en la Iglesia sino hasta el Concilio Vaticano II. Durante los años cuarenta y cincuenta, la mayoría de estos teólogos recibieron condenaciones y prohibiciones de parte de Roma ${ }^{11}$.

El Padre Hurtado conoció y fue fuertemente influido por estos movimientos y por la Nouvelle Théologie. Sus estudios de Teología en la Universidad de Lovaina, Bélgica, durante la primera mitad de los años treinta, lo habían puesto en contacto con esta sed de renovación. El estilo de formación abierta de los jesuitas belgas, atentos a las realidades del mundo, y el rico ambiente teológico y espiritual de Lovaina ejercieron una gran influencia sobre él. Un excelente grupo de profesores, activos colaboradores de este nuevo enfoque teológico, prepararían a Hurtado para ir incorporando en su ministerio los profundos cambios que se estaban cuajando ${ }^{92}$.

\section{Inserción en el mundo: sentir el sufrimiento obrero}

Deseoso de renovarse, Alberto Hurtado hizo un viaje a Estados Unidos en 1945. Camino al país del Norte, hizo escala en Costa Rica para conversar con Monseñor Víctor Sanabria, Arzobispo de San José. La conversación cautivó a Hurtado y lo animó en su compromiso social; Sanabria le dijo que había que enamorarse de las encíclicas sociales, porque ellas abordaban teológicamente problemas modernos, y le remarcó que la Iglesia tenía que tomar de una vez por todas partido por los trabajadores, pues había estado mucho tiempo enredada en una postura apologética y alejada

91 Ídem, 119-138; J. O’MAlley, What Happened at Vatican II, 72-78; E. IserLOH, «Movements within the Church and their Spirituality», 869-895.

92 J. Castellón, Padre Alberto Hurtado, 22-26. Ver también F. PArRa, «Teología del Cuerpo Místico, Comunión de los Santos y pensamiento social en san Alberto Hurtado. La influencia de Émile Mersch y Karl Adam». 
de la realidad ${ }^{93}$. Estas ideas atraían mucho a Hurtado. En sus apuntes de clase en la Universidad Católica de Washington, registró en noviembre de 1945: «Elprofesor de religión tiene que estar continuamente readaptando su clase a los problemas de su ambientes ${ }^{94}$. Y en su visita a la JOC en Canadá, en enero de 1946, reflexionó sobre su labor como asesor: «Uno se traslada a su medio de vida: Hay que ir a ver al obrero a su casa, comer con él, confesarlo en su misma casa, si fuere necesario. Conocer los problemas de su mujer, de sus hijos, de su ambientes ${ }^{95}$. En Canadá leyó las actas de las Semanas Sociales de Toulouse y quedó muy desilusionado, porque, según él, se movió en arenas demasiado abstractas y distantes de la realidad, «le faltó realismo... No bubo participación de las grandes corrientes históricas que dividen boy a la bumanidad [...] La mayor parte de los censos separados de la realidad... no nos han interesado [...] El Cristianismo ¿no es acaso una visión de la historia? ¡Faltaban directivas precisas de acción. $\rangle^{96}$.

La inserción en la realidad comenzó a ser clave en el discurso del Padre Hurtado. La recristianización de la sociedad no era posible si la Iglesia no asumía este desafío de estar cerca del pueblo. No solo eran necesarios más sacerdotes, sino que la Iglesia en su conjunto, laicos y clérigos, tenía que acercarse a la realidad de pobres, trabajadores, enfermos y pecadores. A su juicio, la Iglesia de Estados Unidos daba una lección en eso, «la vida católica obrera en Estados Unidos no ha sido separada de la realidad del mundo obrero y en su lucha por una mejor vida el obrero católico Norte Americano no tiene que esconderse de la Iglesia, sino sabe que encuentra en ella su mejor aliada, pues es movimiento de avanzadas ${ }^{97}$. Y el sacerdote era el primero que debía estar comulgando con esa realidad: «El sacerdote en todas partes... pero en todas: en el sindicato. En Norte América, en las grandes huelgas: ;dos sacerdotes en medio de su piquetess ${ }^{98}$. Su autocrítica eclesial fue severa en este punto, la Iglesia había perdido terreno porque había estado hablando solo del cielo y desentendiéndose de los problemas humanos, que eran los que en realidad preocupaban a la gente; si la Iglesia se hiciera cargo también de estos problemas, los prejuicios sobre ella desaparecerían ${ }^{99}$. Una acción social más decidida por parte de los católicos, revertiría la crisis de la

93 [Diario de viaje a EE. UU. I], 1945, APH s16y01.

94 Cristocentrismo en la enseñanza de la Religión, [1945], APH s68y15.

95 JOC, [1945], APH s61y08f.

96 Semana Social de Toulouse, [1945], APH s61y08h.

97 Los católicos y el problema social en Estados Unidos, [1946], APH s15y03.

98 S. Fernández (ed.), Un Disparo a la Eternidad, 254.

99 Actitud de espíritu con que ha de abordarse el OSC, [1946], APH s24y05. 
Iglesia: «Cuando los pobres ven, palpan su dolor y nos miran a nosotros cristianos ¿qué tienen derecho a pedirnos? ¿A nosotros que creemos que Cristo vive en cada pobre? ¿Podrán aceptar nuestra fe si nos ven guardar todas las comodidades, odiar al comunismo por lo que pretende quitarnos más que por lo que tiene de ateo? ¿Cuál debe ser nuestra actitud? ;Sentido social!, servir, dar amar. Llenar mi vida, de los otros $\rangle^{100}$. A los jóvenes, en el retiro de semana santa de 1947, les urgió a asumir la crisis del mundo como la crisis de la Iglesia y a despojarse del «traje medieval» para que el mundo moderno fuera cristiano; y les atizaba a ser coherentes: si el cristiano se levanta contra el nazismo y el comunismo, "zipor qué no me levanto ante la opresión [de los] pobres? ${ }^{101}$

Su viaje a Europa, a mediados de 1947 alimentó aun más esta convicción y lo conectó nuevamente con las corrientes renovadoras en la teología y la pastoral. En su entrevista con el Papa Pío XII, le señaló que se acercaba una inmensa tragedia que «nos va a pillar desprevenidos», pues la situación social en Chile era escandalosa y la Iglesia no tenía ninguna obra con los obreros, por el contrario, obispos y clero aparecían demasiado ligados a los intereses capitalistas. A su juicio, los obispos en Chile eran piadosos, pero alejados de los «reales movimientos de masa». Y esto, por supuesto, afectaba las vocaciones: «Si se viese a la Iglesia más lanzada en la solución de los problemas humanos, se podría esperar que bubiese más vocaciones, porque en realidad puedo atestiguar que la mayor parte de las vocaciones de estos últimos años han sido movidas por su responsabilidad sociabi ${ }^{102}$. En Francia aprovechó de estudiar el proceso de descristianización de la sociedad francesa ${ }^{103} \mathrm{y}$ los nuevos métodos pastorales impulsados por el Cardenal Emmanuel Suhard, Arzobispo de Paris ${ }^{104}$. Asimismo, asistió al Congreso de Pastoral Litúrgica donde se encontró con los exponentes de la Nouvelle Théologie, como Congar, Daniélou y Guardini ${ }^{105}$; dos meses antes, en julio, había estado en las Semanas Sociales de París con teólogos de la talla de MarieDominique Chenu, Henri de Lubac y Maurice Blondel, que serían claves en el Concilio Vaticano II, pero que a muchos hacían arrugar la nariz esos

\footnotetext{
100 S. FERnÁndez (ed.), La Búsqueda de Dios, 86.

101 La misión del cristiano, [1947], APH s48y18.

102 Informe del Padre Hurtado, [1947], APH s70y016.

103 Carta a Luis Williamson, 1947, APH s70y037.

104 S. FERNÁNDEZ (ed.), Cartas e Informes, 155.

105 M. Clavero, «Un punto de inflexión en la vida del padre Alberto Hurtado. Itinerario y balance de su viaje a Europa, de 1947», Teología y Vida XLVI (2005): 291-320.
} 
días; no por nada Hurtado escuchó a alguno llamar a esa Semana Social, «la semana de los herejes» ${ }^{106}$.

En su pieza de la comunidad jesuita de Études, en París, apuntó que eran pocos los sacerdotes y seglares verdaderamente preparados para el apostolado moderno, los predicadores estaban hablando por encima de la cabeza de sus oyentes, se predicaba una doctrina segura, pero el resultado era superficial ${ }^{107}$. Es necesario, escribía, tomar las miserias de nuestro pueblo, «su dolor debe hacerme mal: la falta de higiene en sus casas, su alimentación deficiente, la falta de educación de sus hijos, la tragedia de sus bijas: que todo lo que los disminuya, me desgarre a mí también» ${ }^{108}$. Solo a través de un compromiso con lo temporal se podría dar verdadero testimonio de Cristo y sería posible, así, contrarrestar la pérdida del sentido de Dios que, según él, entristecía la época moderna ${ }^{109}$. La experiencia de los sacerdotes obreros en Francia dejó una profunda marca en Hurtado; ellos simbolizaban, a su juicio, el esfuerzo incipiente de la Iglesia por insertarse y acompañar así al pobre en su indigencia, al trabajador en su fábrica, a las familias en sus vicisitudes.

\section{Cuando «la Iglesia somos todos» era novedad}

La monumental cantidad de trabajo del Padre Hurtado le obligó a contar con los laicos si quería ver crecer sus proyectos sociales. De hecho, esta fue su opción desde un comienzo en el Hogar y la ASICH, todo en manos de laicos. En una entrevista sobre el Hogar de Cristo, en octubre de 1946, Marina de Navasal señalaba: «Por último, el Padre Hurtado nos da otros datos sobre la Fundación; presidente de ella, es don Ramón Venegas Carrasco; vicepresidente, don Eugenio Browne. Y entre los demás. Las señoras: Beatriz Marescoti, Rebeca Julian de Franke, Inés Edwards, Mimi Peña y muchísimas otras que sería largo enumerar -dice el padre Hurtado-. Pero, gracias a ellas, a su entusiasmo y a su perseverancia, se ha becho todo» ${ }^{110}$. Y no era una declaración de buena crianza, Hurtado estaba orgulloso que la dirección y el día a día del Hogar era llevado por los laicos y no se había personalizado en él. Sus colaboradoras se lo hacían saber y él estaba de acuerdo: «En cuanto a su criterio respecto a

\footnotetext{
106 Santiago a Europa, 1947, APH s16y15.

107 S. Fernández (ed.), La Búsqueda de Dios, 32-33.

108 Ídem, 62.

109 S. FERNÁNDEZ (ed.), Cartas e Informes, 156.

110 Entrevista de Marina Navasal al Padre Hurtado, Santiago, octubre 25 de 1946, Hogar de Cristo, [1946], APH s10y36.
} 
impersonalidad de la labor del Hogar de Cristo estoy en un quinientos porciento de acuerdo con Ud. Para obtenerla creo que han servido muchisimo mis ausencias del país $y$ la insistencia en una idea me parece fundamentab ${ }^{111}$. Asimismo, Hurtado se esforzaba por marcar que los iniciadores de la ASICH fueron «un grupo de seglares» y que su objetivo era precisamente empoderar a los obreros mismos; «trabaja en la ASICH -decía- un grupo bien compacto de dirigentes obreros y empleados de gran valor, con inmenso espiritu de sacrificio y honrader que ba tomado en sus manos el movimiento y lo dirige con gran seguridad y prudencias ${ }^{112}$.

El Padre Hurtado se fue haciendo consciente de que la cercanía de la Iglesia con los más pobres no pasaba solo por un esfuerzo de los sacerdotes, todo cristiano estaba llamado a ello; había que hacer un esfuerzo por confiar en los laicos. Al papa Pío XII le decía: «Para llegar mejor al pueblo, sería necesario facilitar la asistencia a misa en los barrios populares. Sería también necesario hacer un llamado a la confianza de los laicos para que ellos realicen una acción sociabi ${ }^{113}$. La acción y el discurso de Hurtado estos años sintonizaron agudamente con los cambios eclesiales en desarrollo. Por más de mil quinientos años el laicado había sido definido negativamente, laicos eran los «no clérigos» y los «no monjes»; no estaban llamados a la santidad y de hecho no tenían ninguna función o poder en la Iglesia. Como Paul Lakeland señala, «el clero actuaba, el laico recibia; el clero santificaba, el laico era santificado; el clero enseñaba, el laico aprendía; el clero gobernaba, el laico era gobernado» ${ }^{114}$. El Concilio de Trento no había dicho nada acerca del rol del laico, pese a que Lutero cuestionó como sobreestimado el poder de la jerarquía y promovió la participación del cristiano común, especialmente a través del uso de la Biblia y la predicación de la Palabra. Sin embargo, la Ilustración despertó la sed de participación de los laicos y de influir en el destino de la Iglesia; ante los «enemigos» traídos por la modernidad, el laicado se movilizó en defensa de los intereses de la Iglesia. En el siglo XIX, el laicado sintió que tenía la responsabilidad de reconquistar el mundo para Cristo y proliferaron así miles de confraternidades y asociaciones laicas, bajo supervisión de la jerarquía ${ }^{115}$.

111 Carta a Marta Holley, 1948, APH s65y81.

112 Informe del Padre Hurtado, [1952], APH s64y60.

113 Informe del Padre Hurtado, [1947], APH s70y016.

114 P. Lakeland, «The Laity» en R. Bulman - F. Parrella, From Trent to Vatican II. Historical and Theological Investigations, 193. La traducción es mía.

115 M. A. Huerta, Catolicismo Social en Chile (Santiago 1991) 182-216; P. Lakeland, «The Laity», 196-199. 
Durante el siglo XX, la devoción a la santidad en el diario vivir se fue haciendo cada vez más popular; los cristianos podían asegurar la salvación si estaban preocupados de los demás y del cumplimiento de sus deberes cotidianos. Se comenzó lentamente a valorar como «religiosos» no solo los actos directamente relacionados con Dios, como la oración, la meditación y la liturgia, sino también toda actividad que se hiciera en honor del Señor. La vida y el mensaje de Teresita de Lisieux generaron gran devoción, porque, a pesar de ser ella una religiosa, enfatizaba precisamente la santidad en lo sencillo y lo cotidiano ${ }^{116}$. Como se señaló, la Acción Católica dio un nuevo impulso a esta espiritualidad en la Iglesia, el laico fue reconocido como un miembro del Cuerpo de Cristo, capaz de participar en el apostolado de la jerarquía. Mientras Pío X, en 1906, señalaba que la Iglesia era una sociedad desigual en la que la jerarquía poseía la autoridad y a los laicos, como un dócil rebaño, les correspondía la obediencia ${ }^{117}$, quince años después, el Papa Pío XI animaba la participación activa del laicado en la renovación del Reino de Cristo y la recristianización de la sociedad $^{118}$. Casi 25 años más tarde, en 1946, el Papa Pío XII, ya con otro lenguaje, señalaba al Colegio de Cardenales que los laicos «son la Iglesia» ${ }^{119}$. Especialmente el trabajo de Yves Congar sobre historia de la Iglesia y eclesiología aceleró esta apertura a una nueva comprensión del laicado y de la Iglesia; la noción de «Pueblo de Dios» y de Iglesia como «comunión» fue desarticulando la concepción dominante de sociedad desigual. Esta nueva comprensión encontraría un lugar preferencial en el Concilio Vaticano II $^{120}$.

El Padre Hurtado estuvo con Congar en el Congreso de Pastoral Litúrgica en Lyon, en 1947, y fue testigo del quiebre del antiguo paradigma: «iHay acaso un apostolado jerárquico y un apostolado no jerárquico? ¿El apostolado no consiste en continuar la misión confiada por Cristo a sus Apóstoles, misión espiritual ante todo? Y sin embargo jel fermento cristiano no ha de penetrarlo todo, para elevarlo todo? ¿Los jóvenes y los adultos consagrados a la Acción Católica deben limitar su apostolado al terreno espiritual o dar un testimonio aún en las manifestaciones profanas de la vida? $\rangle^{121}$. Son preguntas dolorosas, decía Hurtado, pero había

116 E. IserLoH, «Movements within the Church and their Spirituality», 894-895.

117 Pío X, EncíclicaVehementer Nos, febrero 11, 1906, no 8.

118 Pío XI, Encíclica Ubi Arcano Dei, diciembre 23, 1922.

119 M. Sullivan, The Road to Vatican II. Key Changes in Theology (New York 2007) 70.

120 Ídem, 60-70.

121 Acción Católica, [1947], APH s19y01. 
que enfrentarlas porque se abría con ellas un nuevo campo de acción para los cristianos: el mundo. En una charla a los obreros, en el asentamiento minero de Humberstone en 1948, les señaló que la solución tenía que venir de ellos mismos: «El que sufre principalmente es el propio obrero. Es de él de quien ha de venir la solución ${ }^{122}$. A un grupo de mujeres en un retiro las animó a sentirse parte de la misión: «No dejéis la responsabilidad solamente a los sacerdotes, idea terriblemente errónea en nuestra mente cristiana. No es cierto que la Iglesia son sólo los obispos y sacerdotes; ¿quién es más cuerpo, la cabeza o el pie? Ambos igualmente, y tiene solidaridad. La Iglesia somos todos, vosotros tanto como el Cardenal de Santiago y el Papa Pío XII. Ustedes tienen tanto la responsabilidad (la católica que trabaja en el Banco Central) como el colegio Cardenalicio» ${ }^{123}$. Los laicos no eran solo auxiliares, sino responsables del Reino ${ }^{124}$. Pocos días antes de morir, el Padre Hurtado redactó los estatutos de la Fraternidad del Hogar de Cristo, una asociación para laicos que se consagraba, por medio de votos, al servicio del pobre. En estos estatutos señaló que se había producido un cambio en la Iglesia, ya que ésta comenzaba a reconocer que también los laicos podían alcanzar la santidad por los medios que antes estaban reservados solo a los religiosos: «Para esta posibilidad de santificación, de vida consagrada, de entrega a Dios, no se tomarán medios extraordinarios, se tomarán los medios del mundo: la vida laica, la profesión, el matrimonio, la educación de los hijos» ${ }^{125}$.

\section{El oficio del sacerdote es servir}

En diciembre de 1948 Hurtado pidió a un grupo de señoras que no se quejaran de la Iglesia, pues ellas también eran Iglesia y tenían una misión que cumplir, «mientras un seglar no ha cumplido su misión no puede quejarse de un sacerdote» ${ }^{126}$. Hurtado lo decía no solo porque quería animar la responsabilidad laical sino porque sabía también que las críticas contra los sacerdotes abundaban, «vivimos en una época en que nosotros sacerdotes sentimos la oposición, a veces el odio, al menos el recelo del mundo. Esto no es nuevo, pero tal vez abora está más acentuado que nunca» ${ }^{127}$. Esta oposición, a veces, tenía su razón de ser. Las iglesias y capillas en Chile seguían funcionando con un calendario solar, se abrían en la mañana y se cerraban a las

122 Humberstone, [1948], APH s26y11e.

123 Nuestra responsabilidad en la vida, 1948, APH s47y26.

124 Moyens de formation mis en valeur par la JOC, [1947], APH s17y05.

125 Fraternidad del Hogar de Cristo, 1952, APH s64y62.

126 Nuestra responsabilidad en la vida, 1948, APH s47y26.

127 Mundo y sacerdote, [1949], APH s56y15. 
siete de la tarde, impidiendo a los trabajadores pasar a rezar después de la jornada, pese a las facilidades traídas por la luz eléctrica ${ }^{128}$; para los jóvenes los sacerdotes olían a cosas viejas, en sus piadosas caras se reflejaba la desconfianza a una vida fresca y una aprehensión a las alegrías naturales, en todo buscaban constantemente el pecado y la vida misma les parecía un peligro ${ }^{129}$; por miedo a que una mayor libertad afectase su vida sacerdotal, muchos restringían su acción a la misa y a las prácticas tradicionales de piedad, no iban a lugares públicos ni visitaban a sus feligreses en sus casas, generando así una distancia insalvable con la gente común ${ }^{130}$. El Padre Hurtado fue testigo en Europa de la constatación que hicieron teólogos, sacerdotes y laicos, sobre la necesidad de reforma: «La lengua de la Iglesia con sus ceremonias, incomprensibles» ${ }^{131} \ldots$ ¿ será posible para acercar las masas a la Iglesia obtener la Misa en la tarde y la antemisa en lengua vulgar? ${ }^{132} . .$. «La enseñanza que damos, demasiado jurídica. Enseñamos demasiado lo jurídico y muy poco lo teológico del Domingo [...] Todo se reduce a obligarles a ir a la Misa... ${ }^{133}$; y como consecuencia, se planteaba la necesidad de un sacerdocio distinto: «El sacerdote no [puede] conversar con los hombres porque no conoce nada de lo que es la preocupación [de los] hombres sin trabajo. Las dificultades financieras, del patrón, nada... El sacerdote que va al seminario a los 11 años...» ${ }^{134}$.

La nueva comprensión del laicado y de la necesidad de inserción de la Iglesia en el mundo de los pobres supuso para Alberto Hurtado una evolución en su concepción del rol de sacerdote. El sacerdote siguió teniendo para él una centralidad fundamental e insustituible, su misión siguió siendo «la más grande, la más sublime, la más necesaria misión que existe sobre la tierra ${ }^{135}$, sin embargo, en sus últimos años enfatizó la labor del sacerdote más como un apoyo, un guía, un formador. El sacerdote debía estar siempre al servicio del pueblo cristiano, su autoridad era un servicio ${ }^{136}$, «la misa

\footnotetext{
128 G. WeIgeL, «Chilean Impressions», Box 1 Folder 78.

129 Ibídem.

130 G. Weigel, «The Chilean Tohu-Webohu», Box 1 Folder 79.

131 Prensa, [1947], APH s17y04a.

132 Misión de París, [1947], APH s53y24.

133 En Francia ¿se santifica el Domingo?, [1947], APH s61y01.

134 Prensa, [1947], APH s17y04a.

135 El mundo y Jesús, [1946], APH s56y24.

136 Jesús Buen Pastor, modelo nuestro, [1945], APH s36y14.
} 
no es para el sacerdote, es para el pueblo de Dios ${ }^{137}$; en unas notas personales apuntaba en 1947: «El oficio del sacerdote es servin ${ }^{138}$. El sacerdote era el que debía sostener y animar, pero no el jefe; su misión era educar, mantener el fuego, conducir a Cristo, aportar desde la luz del Evangelio y el magisterio, pero no dar soluciones hechas: «Los seglares serán los apóstoles directos... Alpasar a la acción, el sacerdote será el animador que sostiene y da ánimo, pero no el jefe del laicado. Jamás el sacerdote será jefe obrero, ni bajo el pretexto de ir más aprisa o de hacer mejor. La acción será la de los laicos» ${ }^{139}$. En el último libro publicado por el Padre Hurtado, Sindicalismo, a diferencia de todos los anteriores, no apareció el sacerdocio como solución, y fue completamente dirigido a los laicos, por primera vez sin alusiones vocacionales implícitas o explícitas; a su vez, su libro póstumo Moral Social, señaló que el principal medio de acción del sacerdocio era su testimonio pobre y desinteresado, y su misión, la formación y educación de los cristianos ${ }^{140}$.

Incluso la comprensión de su propia identidad sacerdotal se vio tocada; él mismo se consideró llamado a ser particularmente un animador y formador. En 1947, le comentó al Padre General en su entrevista en Roma que el corazón de sus planes para el futuro era preparar dirigentes obreros y patrones jóvenes en área social y crear un centro de estudios y acción social completamente a cargo de seglares ${ }^{141}$, él estaría animándolos y formándolos. Su giro hacia lo social generó críticas, una de ellas fue su supuesta incompetencia en el área social y económica; Hurtado respondió a esa crítica señalando que era consciente de su limitación técnica, pero que creía que su fortaleza estaba en su capacidad de ser un «animador sociabi ${ }^{142}$. Él animaría a los laicos en la labor social que solo ellos, con su competencia particular, podían realizar en el mundo. Cuatros meses antes de morir, en la celebración de los 25 años de sacerdocio de su amigo el Obispo Manuel Larraín, predicó sobre la misma apertura con que la que él vivió su propio sacerdocio: «El sacerdote no está llamado a ser tan sólo el ministro del culto, su sacerdocio no será solamente por estos actos intermitentes, sino por todo su ser, por todo lo que es, en cada hora de su vida, en la más modesta ocupación,

\footnotetext{
137 Sagrada Eucaristía, APH s50y22.

138 Miles Christi, [1947], APH s59y18.

139 El sacerdote frente al mundo obrero, APH s56y23.

140 P. Miranda (Ed.), Moral Social. Obra póstuma de San Alberto Hurtado, SJ (Santiago: Ediciones Universidad Católica de Chile, 2006), 377-379.

141 Carta a J.B. Janssens, 1947, APH s70y102.

142 Carta a Carlos Aldunate, 1948, APH s62y059.
} 
como en la más solemne. Consagrará porque ha sido consagrado, siempre pronto a santificar los valores humanos» ${ }^{143}$.

\section{Se buscan sacerdotes (distintos)}

Por supuesto, esto supuso cierto ajuste en su pastoral vocacional. Estos años el Padre Hurtado vinculó más estrechamente su trabajo de promoción del sacerdocio con su acción social, pues creía que en el contacto con los más pobres y con las necesidades materiales y espirituales del país, los jóvenes escucharían el llamado más diáfanamente. La escasez de vocaciones tenía su origen, según su parecer, en la secularización: la «disminución del espiritu cristiano», el «ambiente hostil a la religión» y el consiguiente «debilitamiento de lo religioso» en la sociedad. Es por eso que para tener vocaciones había que volver a «sembrar a Cristo» y renovar los deseos de santidad ${ }^{144}$. ¿Y cómo? Ya lo venía diciendo desde los comienzos de su ministerio: a través de la insistencia en la vida sacramental, la dirección espiritual, la enseñanza religiosa, los ejercicios espirituales (que dan el «gran sacudón»), la Acción Católica y la vida parroquial. Sin embargo, estos años enfatizó un medio concreto, una especial «orientación social» en la educación del joven: "Que no vean [los jóvenes] su vida cristiana sólo como un problema de salvación, sino de responsabilidad con Cristo y las almas» ${ }^{145}$. Las vocaciones vendrían si los jóvenes veían una actitud más valiente de parte los mismos sacerdotes, más preocupados de los grandes problemas humanos, sobre todo de los sociales, «que el sacerdote no esté confinado únicamente a hablar del cielo, sino también de esta tierra en que se juega la causa de las almas, en que se traba la batalla por el reino de Cristo» ${ }^{146}$. El nuevo sacerdote debía ser enérgico y positivo hacia el mundo: "Hacen falta esos caracteres positivos, hombres decididos; y también una pedagogía positiva, no solamente probibitiva» ${ }^{147}$. Pero al mismo tiempo debía ser un inconformista, no para traer miedo a la gente, ya bastante asustada con una predicación moralizante, sino para decir la verdad sobre la injusticia en el mundo, a través de un «ministerio de inquietud» ${ }^{148}$. Y para ello debía tomar la realidad en serio ${ }^{149}$, tener los pies bien puestos sobre

\footnotetext{
143 Homilía por los 25 años de sacerdocio de Manuel Larraín, 1952, APH s47y22.

144 Causas de la escasez de vocaciones y sus remedios, [1946], APH s56y13.

145 Ibídem.

146 Ibídem.

147 Vocación y profesión, [1949], APH s56y08.

148 Homilía por los 25 años de sacerdocio de Manuel Larraín, 1952, APH s47y22.

149 T. Mifsud, El Sentido Social: El legado ético del Padre Hurtado (Santiago 2005), 157.
} 
la tierra: «El hombre moderno aunque sea sacerdote no puede librarse del ambiente pagano del mundo que lo rodea: revistas, periódicos, radios, avisos, procesos judiciales, debates parlamentarios. Ha de conocer ese mundo, juzgarlo y superarlo. Si no, no podrá convertirlo. Un sacerdote será tanto mejor apóstol cuanto más conocedor sea de su ambiente $y$ de su tiempor ${ }^{150}$. En definitiva, el candidato al sacerdocio, para el Padre Hurtado, debía buscar, sobre todo, recuperar el sentido de Dios en un mundo que lo tenía extraviado ${ }^{151}$, viviendo «una aplicación de la santidad a lo sociabi ${ }^{152}$. La credibilidad del sacerdote en el mundo moderno pasaba por esa comprensión profunda de la lucha por la vida del ser humano contemporáneo, solo en sintonía con los pobres y sufrientes el sacerdote podía ser testimonio del amor de un Dios encarnado en la historia ${ }^{153}$.

\section{Epilogo}

Fruto de la lectura cronológica de los escritos del Padre Hurtado, he querido sintetizar tres puntos fundamentales en su vida y ministerio. En primer lugar, mostrar que su ministerio estuvo marcado por una percepción de crisis social y crisis moral que invadió a la Iglesia en su conjunto; crisis que, a su juicio, encontraba su origen en el proceso de secularización que vivía la sociedad y la cultura. En segundo término, este ministerio se vio muy influido por su esfuerzo por abordar esta crisis. La promoción del sacerdocio y su trabajo con jóvenes eran medios que el Padre Hurtado consideraba fundamentales para la recristianización de la sociedad; la falta de vocaciones al sacerdocio fue presentada por él como el problema más urgente, en vistas a detener el avance de la indiferencia religiosa y la increencia. Por último, desde fines de 1944 se produjo un giro en la acción y el discurso del Padre Hurtado; su cercanía con los pobres y el trabajo codo a codo con los laicos lo llevó a matizar el foco de su predicación: el Padre Hurtado, en sintonía con los signos de los tiempos, vislumbró que la recristianización de la sociedad pasaba más bien por la solidaridad afectiva de la Iglesia con el mundo moderno, especialmente con los pobres y sufrientes, y por un trabajo activo de la Iglesia en su conjunto, laicos y clérigos.

\footnotetext{
150 La formación del sacerdote, [1949], APH s40y11.

151 Creación, contacto personal con Dios, [1951], APH s31y11a.

152 Carta a Carlos Hurtado, 1946, APH s70y086.

153 Causas de la escasez de vocaciones y sus remedios, [1946], APH s56y13.
} 
Resumen: Este artículo, a partir de la lectura cronológica de todos los escritos de San Alberto Hurtado conservados en el archivo de la provincia chilena de la compañía de Jesús, sistematiza y explicita la preocupación del Padre Hurtado acerca del lugar y la suerte de la Iglesia en el mundo moderno, junto con la evolución de su pensamiento en este sentido (desde una concepción de Iglesia clerical y hierática a una más comunitaria y participativa). Frente a la crisis generalizada que provocó la modernidad y la secularización, en la tesis de la presente investigación, San Alberto Hurtado respondió con una acción pastoral-vocacional que buscaba suscitar más y mejores sacerdotes para enfrentar dicha crisis.

Palabras clave: San Alberto Hurtado, acción pastoral, vocaciones, eclesiología.

Abstract. This article, based on a chronological reading of all the writings by St. Alberto Hurtado preserved in the Chilean Province of the Society of Jesus, systematizes and specifies Father Hurtado's concern over the place and fate of the Church in the modern world, as well as the evolution of his thinking in this sense (from a conception of a clerical and hieratic Church to one more community-based and participatory). This research proposes that St. Alberto Hurtado, when faced with the widespread crisis caused by modernity and secularization, responded with vocational pastoral action designed to engender more and better priests to confront such crisis.

Keywords: St. Alberto Hurtado, pastoral action, vocations, ecclesiology. 